\title{
Distribution and association of hs-CRP with cardiovascular risk variables of metabolic syndrome in adolescent learners
}

\author{
Authors: \\ Megan A. Rensburg ${ }^{1}$ \\ Tandi Matsha ${ }^{2}$ \\ Mariza Hoffmann ${ }^{1}$ \\ Mogamat S. Hassan² \\ Rajiv T. Erasmus ${ }^{1}$ \\ Affiliations: \\ ${ }^{1}$ Division of Chemical \\ Pathology, National \\ Health Laboratory Service, \\ Tygerberg Hospital, \\ Stellenbosch University, \\ South Africa \\ ${ }^{2}$ Faculty of Health and \\ Wellness Sciences, Cape \\ Peninsula University of \\ Technology, South Africa \\ Correspondence to: \\ Megan Rensburg \\ Email: \\ rensburg@sun.ac.za \\ Postal address: \\ PO Box 19113, Tygerberg \\ 7505 , South Africa \\ Dates: \\ Received: 14 Mar. 2011 \\ Accepted: 19 Jan. 2012 \\ Published: 04 June 2012 \\ How to cite this article: \\ Rensburg MA, Matsha T, \\ Hoffmann M, Hassan MS, \\ Erasmus RT. Distribution and \\ association of hs-CRP with \\ cardiovascular risk variables \\ of metabolic syndrome in \\ adolescent learners. Afr J \\ Lab Med. 2012;1(1), Art. \\ \#10, 6 pages. http://dx.doi. \\ org/10.4102/ajlm.v1i1.10
}

(C) 2012. The Authors Licensee: AOSIS OpenJournals. This work is licensed under the Creative Commons Attribution License.
Objective: Metabolic syndrome (MetS) and its associated cardiovascular risk are on the increase in children. High-sensitivity C-reactive protein (hs-CRP) has emerged as a useful marker for inflammation associated with atherosclerosis and cardiovascular disease. Our aim was to determine the distribution of hs-CRP in an effort to identify the MetS variable that is critical in modulating plasma CRP levels in a population of South African adolescents.

Design: A cross-sectional analytical study design was used for this investigation, where the dependent and independent variables were measured simultaneously.

Methods: Anthropometric variables, blood pressure, fasting blood glucose and lipids were performed on 324 consenting learners aged 15-18 years from three different ethnic groups (Black, White and Coloured). The National Cholesterol Education Program Adult Treatment Panel III (NCEP ATP III) for ages 15-18 year olds was used to define MetS.

Results: The prevalence of MetS and obesity was 3.7\% and 7.1\%, respectively. The hs-CRP levels were significantly higher in subjects with a waist-circumference greater than the 90th percentile $(p<0.01)$ and in obese learners with MetS, but was lower in adolescents with normal weight and MetS. Median hs-CRP levels increased with an increasing number of metabolic abnormalities and exceeded $3 \mathrm{mg} / \mathrm{L}$ in $19 \%$ of adolescents. Gender and ethnic differences were observed.

Conclusion: Our findings suggest that obesity and waist circumference appear to be major mediators of hs-CRP levels in South African adolescents.

\section{Introduction}

Globally, obesity and its accompanying metabolic complications are on the increase. Childhood obesity has reached epidemic proportions and is one of the most serious public health problems facing the developed and, increasingly, the developing world. ${ }^{1}$ Metabolic syndrome (MetS), a constellation of interrelated conditions of insulin resistance, hyperlipidaemia, hypertension and obesity, is one of the recognised complications or associations of obesity. A pro-inflammatory and pro-thrombotic state contributing to endothelial dysfunction is a common feature of those with MetS. ${ }^{2}$ It is well recognised that inflammation plays a key role in the pathophysiology of atherosclerosis and cardiovascular disease (CVD). ${ }^{3}$

Markers of endothelial dysfunction and inflammation include tumour necrosis factor-alpha $(\mathrm{TNF}-\alpha)$, the interleukins (IL) and C-reactive protein (CRP). TNF- $\alpha$ is a cytokine secreted from endothelial and smooth muscle cells, macrophages and fat cells. It enhances monocyte recruitment into developing atherosclerotic lesions and therefore links obesity with atherosclerosis. ${ }^{4}$ IL- 6 is the major pro-coagulant cytokine. It increases plasma levels of plasminogen activator inhibitor type 1, fibrinogen and CRP. Lifestyle modifications, including a Mediterranean-style diet and weight loss, reduce serum concentrations of IL-6, IL-7, and IL-18. ${ }^{5}$ Patients with coronary heart disease have markedly elevated levels of IL-1, especially those with unstable disease. ${ }^{6}$

Pro-inflammatory cytokines, including IL1- $\beta$, IL-6 and TNF- $\alpha$, are released from macrophages within the vessel wall during an inflammatory response. ${ }^{4}$ These cytokines mediate distant inflammatory effects, including activation of hepatic genes encoding acute-phase reactants, CRP, fibrinogen and serum amyloid A. CRP induces synthesis of other cytokines, cellular adhesion molecules (CAMs) and tissue factor in monocytes and endothelial cells. ${ }^{4,7}$ Tissue factor activation provides the link between inflammation and coagulation by activating the coagulation cascade.

CRP was traditionally measured in patients to assess and monitor systemic inflammation during an acute infection. Values exceeding $10 \mathrm{mg} / \mathrm{L}$ are accepted as evidence of probable infection 
and/or sepsis. The need for detection very low levels $(<3 \mathrm{mg} / \mathrm{L})$ only became necessary when CRP was discovered to be a useful marker of endothelial dysfunction and future CVD risk. High-sensitivity C-reactive protein (hs-CRP) has emerged as a useful biomarker for vascular inflammation associated with atherosclerosis and it may directly promote atherosclerotic processes. ${ }^{8,9}$ As such, elevated hs-CRP levels, as a response to the increase in the secretion of cytokines of adipose origin, have been used as a marker of cardiovascular risk and diabetes in adults. ${ }^{10}$ Various hs-CRP methods have been introduced, fulfilling the need of measuring CRP levels at these low levels. In apparently healthy adults, hs-CRP levels of more than $3 \mathrm{mg} / \mathrm{L}$ are associated with a high risk of future CVD.

Many studies have examined the clustering of metabolic abnormalities, but the metabolic phenotype continues to be less well understood in children in terms of criteria, prevalence and clinical implications. ${ }^{11}$ Studies have reported high values of hs-CRP amongst obese children and adolescents, indicating a certain level of inflammation.,12 Childhood CRP values have also been shown to predict adult CRP levels independently of other metabolic risk factors. ${ }^{13}$ The US National Health and Nutrition Examination Survey (USNHANES) reported that adolescents with more metabolic abnormalities had higher CRP levels. ${ }^{11}$

The few studies conducted in developing countries have shown a relatively high prevalence of MetS that is paralleled by the increasing obesity in children and adolescents. ${ }^{14}$ A recent study on the prevalence of MetS amongst South African children reported an overall rate of $6.5 \%$ using the National Cholesterol Education Program expert panel on detection, evaluation and treatment of high blood cholesterol - Adult Treatment Panel III (NCEP ATP III) definition. ${ }^{15}$ In South Africa, morbidity and mortality related to non-communicable disease remain prominent, despite the sustained increase in deaths from chronic infections such as HIV and AIDS and tuberculosis. ${ }^{16,17}$ This is particularly important when providing interventions that target CVD and their risk factors, as these chronic conditions place a huge financial and human resource burden on South Africa's health budget. The measurement of hs-CRP concentrations may thus provide an indication of future risk of CVD, which may lead to earlier intervention.

Therefore, the aim of this study was to determine the distribution of hs-CRP in a population of South African adolescent learners and to determine its association with cardiovascular risk factor variables of MetS, in an effort to identify the variable that is critical in modulating plasma hsCRP levels in this population.

\section{Materials and methods \\ Subjects}

Our study population formed part of a larger study involving 1683 learners aged 8-18 years, recruited through a proportionally stratified multistage random sampling technique from government-funded secondary schools in the Western Cape Province of South Africa. The inclusion criteria were, (1) male or female learners aged 15 years -18 years, (2) fasted overnight ( $\geq 10 \mathrm{~h}$ ) and (3) no current or recent history of infectious disease (on self-report). Participants were excluded if the measured hs-CRP values were $>10 \mathrm{mg} / \mathrm{L}$, or if there were any missing data. Recent and/or current infectious disease was excluded by self-report and brief medical examination on the day of sampling.

\section{Measurement of blood pressure, glucose and lipids}

Finger prick blood performed by trained nursing staff was used for the estimation of fasting blood glucose (FBG) and lipid levels using the Accutrend GCT glucometer and CardioChek ${ }^{\mathrm{TM}}$ PA analyser (Polymer Technology Systems, Inc., Indianapolis, USA), respectively. The glucometer coefficient of variation is stated as $<3 \%$ and accuracy is approximately 5\%, when compared to a hexokinase method. The Cardiochek ${ }^{\mathrm{TM}}$ analyser showed reasonable compliance with NCEP goals for coefficients of variation and bias measurements. ${ }^{18}$ Blood pressure measurements were performed using a semi-automatic digital blood pressure monitor (Rossmax Int. Ltd, Taipei, Taiwan) according to World Health Organization guidelines. ${ }^{19}$ The NCEP ATP III for ages 15-18 years were used to define $\operatorname{MetS}^{20}$ (Table 1). Individuals were classified as overweight or obese, according to age and gender, as described by Cole et al. ${ }^{21}$

\section{Measurement of hs-CRP}

Different platforms exist to measure hs-CRP, including turbidimetric, nephelometric and immunometric assays (two-site chemiluminescent). These different methodologies compare well in precision and comparative studies. ${ }^{22}$ Venous blood was collected and the serum was separated and frozen at $-20{ }^{\circ} \mathrm{C}$ before batch analysis. The hs-CRP was measured by an hs-CRP assay, based on the highly sensitive Near Infrared Particle Immunoassay rate methodology (Immage $^{\circledR}$ Immunochemistry System, Beckman Coulter Inc., Brea, USA), with an analytical sensitivity of $0.2 \mathrm{mg} / \mathrm{L}$ and a functional sensitivity of $0.11 \mathrm{mg} / \mathrm{L}$ (measuring range $0.2 \mathrm{mg} / \mathrm{L}-1440 \mathrm{mg} / \mathrm{L}$ ). Participants with hs-CRP concentrations $<0.2 \mathrm{mg} / \mathrm{L}$ had a value assigned to them of $0.2 \mathrm{mg} / \mathrm{L}$.

\section{Statistical analysis}

The STATISTICA 8 software package (StratSoft Inc., Tulsa, USA) was used to perform statistical analyses. Descriptive

TABLE 1: Criteria for the metabolic syndrome are listed below and can be any three of more.

\begin{tabular}{ll}
\hline Criteria list & Components \\
\hline Central obesity $\dagger$ & $>90$ th percentile, age and gender specific \\
FBG & $\geq 5.6 \mathrm{mmol} / \mathrm{L}(100 \mathrm{mg} / \mathrm{dL})$ or known type 2 diabetes \\
Hypertension & $\geq 90$ th percentile for age, sex and height \\
TG & $\geq 1.24 \mathrm{mmol} / \mathrm{L}(110 \mathrm{mg} / \mathrm{dL})$ \\
HDL-C & $\leq 1.04 \mathrm{mmol} / \mathrm{L}(40 \mathrm{mg} / \mathrm{dL})$ \\
\hline
\end{tabular}

Source: Cook S, Weitzman M, Auinger P, Nguyen M, Dietz WH. Prevalence of a metabolic syndrome phenotype in adolescents. Arch Pediatr Adolesc Med. 2003;157:821-827. FBG, fasting blood glucose; TG, triglycerides; HDL-C, high density lipoprotein cholesterol. $\mathrm{FBG}$, fasting blood glucose;
$\dagger$, Waist circumference. 
data are represented as medians because hs-CRP has a nonGaussian distribution and non-parametric statistics have been applied. Other variables, such as glucose, triglycerides and cholesterol, are presented as means, as they follow a normal distribution. For categorical data, group comparisons were performed using the Mann Whitney U-test. A 5\% significance level $(p<0.05)$ was used for determining significant differences.

\section{Ethical considerations}

The study was approved by the Faculty of Health Science Ethics Committee at the University of Stellenbosch and consent to conduct the study was obtained from the Western Cape Education Department. Ethical clearance was given for the collection of venous blood samples from the participants older than 12 years. Finally, a parent or guardian gave consent for the adolescents' participation in this study and the participants themselves assented.

\section{Results}

Three-hundred-and-twenty-nine learners who satisfied the inclusion criteria were recruited for the study. Five were then excluded from this initial study population as a result of hs-CRP levels $>10 \mathrm{mg} / \mathrm{L}$, leaving 324 learners for this study. Of this total, 186 (57.4\%) were female, whilst 138 (42\%) were male. The final study population comprised 136 (42\%) Black learners, 62 (19\%) White learners and 126 (39\%) Coloured learners.

The distribution of hs-CRP was skewed, with higher median hs-CRP concentrations in female learners than male learners $(1.77 \mathrm{mg} / \mathrm{L}$ vs $1.39 \mathrm{mg} / \mathrm{L}$, respectively; $p=0.15)$. Significant racial differences were observed with higher median hs-CRP levels in non-White learners (White - $1.02 \mathrm{mg} / \mathrm{L}$; Black $1.74 \mathrm{mg} / \mathrm{L}$; Coloured - $1.76 \mathrm{mg} / \mathrm{L})$. The hs-CRP levels correlated positively with the learners' body mass index (BMI) and waist circumference, but not with high density lipoprotein cholesterol (HDL-C) or triglycerides.

The prevalence of MetS and obesity was 3.7\% and 7.1\%, respectively. Obesity was higher in all female learners, whilst Coloured learners $(17 \%)$ had a nearly three times higher rate of obesity than White learners (5\%) or Black learners (4\%).

The median hs-CRP levels in the MetS group were $2.56 \mathrm{mg} / \mathrm{L}$, compared to $1.67 \mathrm{mg} / \mathrm{L}$ in those without MetS. The hs-CRP values correlated positively with an increase in the number of MetS components present (Figure 1). Four (33\%) subjects with MetS had a normal weight and their median hs-CRP levels were significantly lower than the obese group (Table 2). Because low-grade systemic inflammation may underlie, at least in part, the clustering of metabolic risk factors, we examined the relationship between hs-CRP concentrations and components of the MetS. There was no association between the individual components, blood pressure, triglycerides, fasting blood glucose and hs-CRP noted. More than $60 \%$ of the participants had HDL values below the cutoff of $1.04 \mathrm{mmol} / \mathrm{L}$, with a mean value $0.97 \mathrm{mmol} / \mathrm{L}$.

There was a significant difference $(p<0.01)$ noted in the CRP concentrations between those with a normal waist circumference, compared to those with a waist circumference greater than the 90th percentile $(1.39 \mathrm{mg} / \mathrm{L}$ vs $3.22 \mathrm{mg} / \mathrm{L}$, respectively).

The hs-CRP levels of $>3 \mathrm{mg} / \mathrm{L}$ were seen in $18.5 \%(n=60)$ of learners. Table 3 compares baseline demographic data and laboratory values for children with CRP levels of $\geq 3 \mathrm{mg} / \mathrm{L}$ and those with CRP levels of $<3 \mathrm{mg} / \mathrm{L}$. These subjects were likely to have higher BMIs, with a higher percentage of obese subjects. However, $13 \%(n=33)$ of children with levels $>3 \mathrm{mg} / \mathrm{L}$ had normal BMI.

\section{Discussion}

Inflammation is an important pathogenic factor in the development of atherosclerosis and coronary heart disease, especially in those with diabetes, obesity and MetS. An important asset of our study is that it investigated the prevalence of MetS in adolescents from three different racial groups in South Africa. MetS, as defined by the modified NCEP ATP III classification, was observed in $3.7 \%$ of all children, with hs-CRP values nearly three times higher in children with MetS compared to those without it. ${ }^{20}$ Previous studies have reported that hs-CRP concentrations correlate with individual components of the MetS. ${ }^{11}$ We observed a positive linear trend in hs-CRP levels, with an increasing number of features of MetS. We also observed no association between the individual components: blood pressure, triglycerides, fasting blood glucose and hs-CRP. Of the

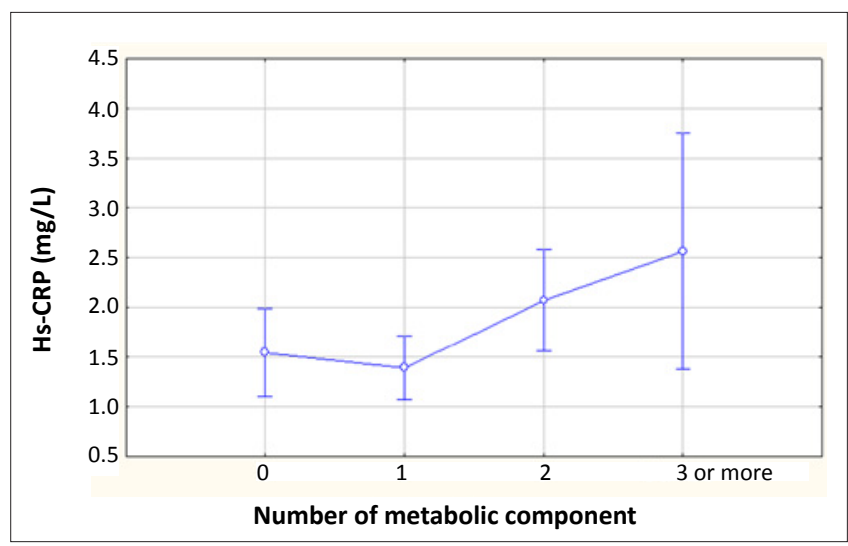

FIGURE 1: Association between the number of metabolic components and high-sensitivity C-reactive protein (Hs-CRP).

TABLE 2: Metabolic syndrome, body mass index (BMI) and high-sensitivity C-reactive protein (hs-CRP) levels amongst the study participants $(N=324)$.

\begin{tabular}{lllcc}
\hline BMI & $\boldsymbol{N}$ & Hs-CRP $(\mathrm{mg} / \mathrm{L})$ & \multicolumn{2}{c}{ Subjects (> 3 components) } \\
\cline { 3 - 5 } & & & Number & Median hs-CRP (mg/L) \\
\hline Normal & 251 & 1.28 & 4 & 0.65 \\
Overweight & 50 & 2.12 & 1 & 0.60 \\
Obese & 23 & 4.00 & 7 & 3.94 \\
\hline Total & $\mathbf{3 2 4}$ & $\mathbf{1 . 6 1}$ & $\mathbf{1 2}$ & - \\
\hline
\end{tabular}


TABLE 3: Baseline demographic data and laboratory results of the study participants $(N=324)$.

\begin{tabular}{|c|c|c|c|c|}
\hline Category & Sub-category & hs-CRP $<3 \mathrm{mg} / \mathrm{L}$ & hs-CRP $\geq 3 \mathrm{mg} / \mathrm{L}$ & $p$-Value \\
\hline Gender & $\begin{array}{l}\text { Male } \\
\text { Female }\end{array}$ & $\begin{array}{l}117(85 \%) \\
147(79 \%)\end{array}$ & $\begin{array}{l}21(15 \%) \\
39(21 \%)\end{array}$ & $\begin{array}{l}- \\
-\end{array}$ \\
\hline Race & $\begin{array}{l}\text { Coloured } \\
\text { Black } \\
\text { White }\end{array}$ & $\begin{array}{l}99(79 \%) \\
111(82 \%) \\
54(87 \%)\end{array}$ & $\begin{array}{l}27(21 \%) \\
25(18 \%) \\
8(13 \%)\end{array}$ & $\begin{array}{l}- \\
- \\
-\end{array}$ \\
\hline Body mass index & $\begin{array}{l}\text { Normal } \\
\text { Overweight } \\
\text { Obese }\end{array}$ & $\begin{array}{l}218(87 \%) \\
37(74 \%) \\
9(39 \%)\end{array}$ & $\begin{array}{l}33(13 \%) \\
13(26 \%) \\
14(61 \%)\end{array}$ & $\begin{array}{l}- \\
- \\
-\end{array}$ \\
\hline Fasting blood glucose (mmol/L) & Mean & 3.86 & 4.25 & $<0.01$ \\
\hline $\mathrm{HDL}(\mathrm{mmol} / \mathrm{L})$ & Mean & 0.97 & 0.99 & 0.68 \\
\hline Triglycerides (mmol/L) & Mean & 0.82 & 0.77 & 0.39 \\
\hline Waist circumference & $\begin{array}{l}<90 \text { th percentile } \\
>90 \text { th percentile }\end{array}$ & $\begin{array}{l}244(85 \%) \\
20(53 \%)\end{array}$ & $\begin{array}{l}42(15 \%) \\
18(47 \%)\end{array}$ & $<0.01$ \\
\hline
\end{tabular}

hs-CRP, high-sensitivity C-reactive protein; HDL, high density lipoprotein.

metabolic variables studied, adiposity, as measured by BMI and waist circumference, was the major predictor of hs-CRP (similar to results obtained from international studies ${ }^{3,11}$ ), suggesting obesity as a mediator of excess CRP seen in the MetS. MetS has been associated with higher CRP levels even in the absence of obesity, $3,11,23$ but this was not observed in our study. Considerably lower hs-CRP levels were observed in children with MetS but with normal weight (also termed metabolically obese, normal-weight children), with the median hs-CRP in this group being $0.65 \mathrm{mg} / \mathrm{L}$, compared to $3.9 \mathrm{mg} / \mathrm{L}$ in the obese group. Previous studies have suggested that metabolically obese but normal-weight individuals are also at an increased risk of developing type 2 diabetes and $\mathrm{CVD}^{24}$; however, this needs to be explored further in our setting in the light of these observations.

This community-based study has demonstrated that hsCRP levels in South African children vary by race and sex and relate adversely to risk variables of MetS. The hs-CRP values ranged from $0.2 \mathrm{mg} / \mathrm{L}$ to $9.9 \mathrm{mg} / \mathrm{L}$, with higher median hs-CRP concentrations in female learners $(1.77 \mathrm{mg} / \mathrm{L}$ vs $1.39 \mathrm{mg} / \mathrm{L})$. Similar observations have been made by Lambert et al. ${ }^{23}$ in 16-year-old children from Quebec, Canada, as well as in the 1999-2000 US NHANES ${ }^{11}$ and the Bogalusa studies ${ }^{3}$. However, in the Taipei Children Heart Study of CRP concentrations no gender differences were observed. ${ }^{25}$ Sex differences have been attributed to the effect of estrogens, which have been implicated in the transcriptional control and clearance of hs-CRP. ${ }^{26}$

As observed in adults, ${ }^{27}$ we found that there were also ethnic differences, with Black and Coloured children having higher hs-CRP levels. Ethnic differences in body fat patterning are thought to account for some of the observed differences. ${ }^{28} \mathrm{In}$ the Bogalusa study, hs-CRP levels showed racial differences and related to measures of obesity. ${ }^{3}$ For a given waist circumference, Black boys and girls from the USA were found to have higher abdominal subcutaneous adipose tissue and lower visceral adipose tissue than their White peers. ${ }^{28}$ Similar observations have been reported in South African children, in whom relatively more subcutaneous fat and greater waist circumference have been observed in stunted girls, which may predispose them to obesity in adulthood..$^{29}$
In the Strong Without Anorexia Nervosa (SWAN) study, which examined 3154 women from different ethnic groups, Afro-American ethnicity was associated with higher hs-CRP levels after controlling for BMI, age and other risk factors, suggesting that genetic variants of hs-CRP and dietary and lifestyle factors could also be contributory factors. ${ }^{27,30}$ The implications of these elevated hs-CRP levels need further study, as South African Black people generally have a better cardiovascular risk profile than other ethnic groups.

Obesity rates were comparable to those observed in many developed countries and obese learners in our study had a significantly higher median hs-CRP $(4.00 \pm 0.58 \mathrm{mg} / \mathrm{L})$ compared to their normal-weight counterparts (1.28 $\pm 0.12 \mathrm{mg} / \mathrm{L}$ ). Because fat distribution appears to have a more important influence on cardiovascular risk factors in young subjects than overall adiposity, abdominal obesity has been identified as the main determinant of several metabolic disorders. ${ }^{31,32}$ The relationship of waist circumference as a measure of abdominal obesity appears to be explained by its strong association with visceral adipose tissue, therefore explaining the strong association with inflammatory biomarkers such as hs-CRP. ${ }^{33}$ We compared the hs-CRP concentration of those with a normal waist circumference to those individuals with a waist circumference greater than the 90th percentile and, as expected, found a significant difference $(p<0.01)$. This finding is consistent with international results and highlights that an increase in abdominal obesity mirrors visceral adiposity and increased inflammation. ${ }^{33}$ Waist circumference, particularly in young South African women, has been shown to be a better predictor of insulin resistance than visceral adipose tissue. ${ }^{34}$

Whilst these results re-affirm that high hs-CRP values are most likely caused by increased fat deposition, we also observed that more than half of the children with hs-CRP $>3 \mathrm{mg} / \mathrm{L}$ were of normal weight, suggesting that a sizable number of apparently healthy children may be at increased cardiovascular risk. Despite these observations in this and other studies, it is not recommended for hs-CRP to be a suitable target for therapeutic intervention as no causal association between hs-CRP and MetS phenotypes has been reported. ${ }^{35}$ One platform to measure CRP, regardless 
of the clinical context, is ideal in the clinical laboratory as it could lead to decreased cost and turn-around-time of analysis, as most laboratories have dedicated instruments for measurement of hs-CRP and batch-analysis is usually performed.

There are several limitations to our findings. The primary limitation is the use of a single hs-CRP measurement. In adults, repeat hs-CRP measurements are recommended, as concentrations are affected by factors such as recent infection and inflammatory conditions. The measurement of other inflammatory biomarkers of endothelial dysfunction could have added more value to the study. Other tests that could have excluded active infection, for example cytokines or white blood cell count, were not conducted. A second limitation is that this was not a national study and excluded learners from private schools. Another limitation is that the study outcomes depended on the definition of MetS. Insulin resistance, the key component of the MetS, was not determined. Furthermore, direct measurement of body fat mass and distribution was not assessed and the study was observational and cross-sectional in nature, making it difficult to differentiate between cause and effect, and associations.

In summary, we have found that hs-CRP is increased in South African adolescents with metabolic abnormalities and the MetS phenotype. Markers of adiposity, such as BMI and waist circumference, appear to be strong mediators of hs-CRP and many learners had hs-CRP levels greater than $3 \mathrm{mg} / \mathrm{L}$, a value that has been used in adults to indicate high CVD risk. In our setting, hs-CRP may be useful marker to assess early atherosclerosis and cardiovascular risk, particularly in those children with normal BMI.

\section{Acknowledgements}

This research was supported by a grant from the National Health and Laboratory Service Research Trust and the Medical Research Council of South Africa. We wish to thank the Cape Peninsula University of Technology for their financial contribution, as well as Professor Martin Kidd for performing the statistical analyses.

\section{Competing interests}

The authors declare that they have no financial or personal relationship(s) which may have inappropriately influenced them in writing this paper.

\section{Authors' contributions}

R.T.E. (Stellenbosch University) was the project leader; all authors contributed equally to experimental and project design and data collection. M.R. (Stellenbosch University), T.M. (Cape Peninsula University of Technology) and R.T.E. wrote the manuscript.

\section{References}

1. Weiss R, Dzuira J, Burgert T, et al. Obesity and metabolic syndrome in children and adolescents. N Engl J Med. 2004;350(23):2362-2374. http://dx.doi.org/10.1056/ NEJMoa031049, PMid:15175438
2. Odrowaz-Sypniewska G. Markers of pro-inflammatory and pro-thrombotic state in the diagnosis of metabolic syndrome. Adv Med Sci. 2007;52:246-250. PMid:18217426

3. Patel DA, Srinivasan SR, Xu J, Li S, Chen W, Berenson GS. Distribution and metabolic syndrome correlates of plasma CRP in biracial (black-white) younger adults: The Bogalusa heart study. Metabolism. 2006;55:699-705. http://dx.doi. org/10.1016/j.metabol.2005.07.015, PMid:16713426

4. Koh KK, Han SH, Quon MJ. Inflammatory markers and the metabolic syndrome. J Am Coll Cardiol. 2005;11:1979-1985.

5. Esposito K, Marfella R, Ciotola M, et al. Effects of a Meditereanean-style diet on endothelial dysfunction and markers of vascular inflammation in the metabolic syndrome. J Am Med Assoc. 2004;292(12):1440-1446. http://dx.doi.org/10.1001/ jama.292.12.1440, PMid:15383514

6. Waehre T, Yndestad A, Smith C, et al. Increased expression of interleukin-1 in coronary artery disease with downregulatory effects of HMG-CoA reductase inhibitors. Circulation. 2004;109:1966-1972. http://dx.doi.org/10.1161/01. CIR.0000125700.33637.B1, PMid:15051633

7. Gabay C, Kushner I. Acute-phase proteins and other systemic responses to inflammation. N Engl J Med. 1999;340:448-454. http://dx.doi.org/10.1056/ NEJM199902113400607, PMid:9971870

8. Pasceri V, Willerson JT, Yeh ET. Direct proinflammatory effect of C-reactive protein on human endothelial cells. Circulation. 2000;102:2165-2168. PMid:11056086

9. Verma S, Li SH, Badiwala MV, et al. Endothelin antagonism and interleukin-6 inhibition attenuate the proatherogenic effects of C-reactive protein. Circulation. 2002;105:1890-1896. http://dx.doi.org/10.1161/01.CIR.0000015126.83143.B4, 2002;105:1890-189

10. Rifai N, Ridker PM. High-sensitivity CPR protein: A novel and promising marker of coronary heart disease. Clin Chem. 2001;47(3):403-411. PMid:11238289

11. De Ferranti SD, Gauvreau K, Ludwig DS, Newburger JW, Rifai N. Inflammation and changes in metabolic syndrome abnormalities in US adolescents: Findings from the 1988-1994 and 1999-2000 National Health and Nutrition Examination Survey. Clin Chem. 2006;52(7):1325-1330. http://dx.doi.org/10.1373/clinchem.2006.067181, PMid:16675506

12. Invitti C, Maffeis C, Giardini L, et al. Metabolic syndrome in obese Caucasian children: Prevalence using WHO-derived criteria and association with nontraditional cardiovascular risk factors. Int J Obes. 2006;30:627-633. http:// dx.doi.org/10.1038/sj.ijo.0803151, PMid:16570092

13. Soriano-Guillén L, Hernanàndez-Garcia B, Pita J, et al. High-sensitivity CRP is a good marker of cardiovascular risk in obese children and adolescents. Eur J Endocrinol. 2008;(159):R1-R4.

14. Kelishadi R. Childhood overweight, obesity and the metabolic syndrome in developing countries. Epidemiol Rev. 2007;29:62-76. http://dx.doi.org/10.1093/ epirev/mxm003, PMid:17478440

15. Matsha T, Hassan S, Bhata A, et al. Metabolic syndrome in 10-16-year-old learners from the Western Cape, South Africa. Atherosclerosis. 2009;205:363-366. http:// dx.doi.org/10.1016/j.atherosclerosis.2009.01.030, PMid:19233359

16. Tollman SM, Kahn K, Sartorius B, Collinson MA, Clark SJ, Garenne ML. Implications of mortality transition for primary health care in rural South Africa: A populationbased surveillance study. Lancet. 2008;372:893-901.

17. Steyn K, Levitt NS, Hoffman M, et al. The global cardiovascular disease risk pattern in a peri-urban working-class community in South Africa. The Mamre study. Ethn Dis. 2004;12:210-233.

18. Panz VR, Raal FJ, Paiker J, Immelman R, Miles H. Performance of the CardioChek ${ }^{\mathrm{TM}}$ $\mathrm{PA}$ and Cholestech $\mathrm{LDX}^{\circ}$ point-of-care analysers compared to clinical diagnostic
laboratory methods for the measurement of lipids. Cardiovasc J S Afr. laboratory methods for the measure
2005;16(2):112-116. PMid:15915279

19. World Health Organization. International society of hypertension guidelines for the management of hypertension. J Hypertension. 1999;17:151-183. PMid:10067786

20. Cook S, Weitzman M, Auinger P, Nguyen M, Dietz WH. Prevalence of a metabolic syndrome phenotype in adolescents. Arch Pediatr Adolesc Med. 2003;157:821827. http://dx.doi.org/10.1001/archpedi.157.8.821, PMid:12912790

21. Cole TJ, Bellizzi MC, Flegal KM, Dietz WH. Establishing a standard definition for child overweight and obesity worldwide: International survey. $\mathrm{Br}$ Med 2000;320:1-6. http://dx.doi.org/10.1136/bmj.320.7244.1240, PMid:10797032, PMCid:27365

22. Rothkrantz-Kos S, Schmitz MPJ, Bekers O, Menheere PCA, Van Dieijen-Visser MP. High-sensitivity C-reactive protein methods examined. Clin Chem. 2002;2:359362.

23. Lambert $M$, Delvin EE, Paradis $G$, et al. C-Reactive protein and features of the metabolic syndrome in a population-based sample of children and adolescents. Clin Chem. 2004;50(10):1762-1768. http://dx.doi.org/10.1373/ clinchem.2004.036418, PMid:15308596

24. Ruderman N, Chisholm D, Pi-Sunyer, Schneider S. The metabolically obese, normal-weight individual revisited. Diabetes. 1998:47:699-713. http://dx.doi. org/10.2337/diabetes.47.5.699, PMid:9588440

25. Wu DM, Chu NF, Shen MH, Chang JB. Plasma C-reactive protein levels and their relationship to anthropometric and lipid characteristics among children. J Clin Epidemiol. 2003;56:94-100. http://dx.doi.org/10.1016/S0895-4356(02)00519-X

26. Laurell C, Rannevik G. A comparison of plasma protein changes induced by Danazol, pregnancy and estrogens. J Clin Endocrinol Metab. 1979;49:719-725. http://dx.doi.org/10.1210/jcem-49-5-719

27. Kelley-Hedgepeth A, Lloyd-Jones DM, Colvin A, et al. Ethnic differences in C-reactive protein concentration. Clin Chem. 2008;54(6):1027-1037. http:// dx.doi.org/10.1373/clinchem.2007.098996, PMid:18403563 
28. Lee S, Kuk JL, Hannon TS, Arslanian SA. Race and gender differences in the relationships between anthropometrics and abdominal fat in youth. Obesity. 2008;16:1066-1071. http://dx.doi.org/10.1038/oby.2008.13, PMid:18356853

29. Mukuddem-Petersen J, Kruger HS. Association between stunting and overweight among 10-15-y-old children in the North West Province of South Africa: The
THUSA BANA Study. Int J Obes. 2004;28:842-851. http://dx.doi.org/10.1038/ sj.ijo.0802586, PMid:14758345

30. Shen J, Ordovas JM. Impact of genetic and environmental factors on hs-CRP concentrations and response to therapeutic agents. Clin Chem. 2009;55(2):256264. http://dx.doi.org/10.1373/clinchem.2008.117754, PMid:19074515

31. Daniels R, et al. Association of body fat distribution and cardiovascular risk factors in children and adolescents. Circulation 1999; 99;541-545. PMid:9927401
32. Revenga-Frauca J, et al. Abdominal fat and metabolic risk in obese children and adolescents. J Physiol Biochem. 2009;65(4):415-420. http://dx.doi.org/10.1007/ BF03185937, PMid:20358355

33. Steinberger J, et al. Progress and challenges in metabolic syndrome in children and adolescents. Circulation. 2009;119:628-647. http://dx.doi.org/10.1161/ CIRCULATIONAHA.108.191394, PMid:19139390

34. Jennings CL, Lambert EV, Collins M, Levitt NS, Goedecke JH. The atypical presentation of the metabolic syndrome components in black African women: The relationship with insulin resistance and the influence of regional adipose metabol.2008.09.007, PMid:19154946

35. Timpson NJ, Lawlor DA, Harbord RM, et al. C-reactive protein and its role in metabolic syndrome: mendelian randomization study. Lancet. 2005;366:19541959. http://dx.doi.org/10.1016/S0140-6736(05)67786-0 